\title{
Penerapan Model AHP Pada Pemilihan Aplikasi Streaming Drama Korea
}

\author{
Fajar Agustini ${ }^{1, *}$, Khoirun Nisa $^{2}$ \\ 1 Sistem Informasi Akuntansi Kampus Kabupaten Karawang; Universitas Bina Sarana \\ Informatika; Jl. Kramat Raya No 98, telp; (021) 21231170; e-mail: fajar.fgt@bsi.ac.id \\ ${ }^{2}$ Sistem Informasi; Universitas Nusa Mandiri; RT.8/RW.13, Cipinang Melayu, Kec. Makasar, \\ Kota Jakarta Timur, telp; 0877-4111-0605; e-mail: khoirun.khn@nusamandiri.ac.id \\ *Korespondensi: e-mail: fajar.fgt@bsi.ac.id
}

Diterima: 22 April 2021; Review: 28 April 2021; Disetujui: 3 Mei 2021, 127-136

Cara sitasi: Agustini F, Khoirun N. 2021. Penerapan Model AHP Pada Pemilihan Aplikasi Streaming Drama Korea. Informatics for Educators and Professionals. Vol 5 (2): halaman 127136

\begin{abstract}
Abstrak: Program aplikasi streaming drama Korea merupakan salah satu perkembangan teknologi yang semakin mendunia, berbagai macam penemuan terbaru teknologi dan berbagai macam aplikasi yang ditawarkan setiap perusahaan akan terus bersaing. Dan bukan hanya satu aplikasi streaming drama Korea saja, melainkan banyak aplikasi-aplikasi streaming lainnya yang bermunculan dan dapat membuat pengguna menjadi ragu untuk memilih aplikasi streaming untuk menonton drama Korea mana yang berkualitas. Pemilihan kriteria yang berguna untuk pemilihan aplikasi streaming drama Korea menggunakan pendekatan Analytical Hierarcy Process dan pengolahan menggunakan software Expert Choice memungkinkan pengguna aplikasi streaming jadi mengetahui bagaimana cara memilih aplikasi streaming untuk menonton drama Korea sesuai yang diinginkan. Populasi dari penelitian ini adalah masyarakat kota Bekasi dengan kuesioner sebanyak 30. Dari hasil penelitian diperoleh VIU adalah alternatif strategis pemilihan aplikasi streaming drama Korea dengan menggunakan Analytical Hierarcy Process yang mendapat prioritas utama dengan bobot sebesar 0,499 atau sebanding dengan $49,9 \%$ dari alternatif yang lain.
\end{abstract}

Kata kunci: Analytical Hierarcy Process, Aplikasi streaming, Drama Korea

Abstract: The Korean drama streaming application program is one of the increasingly global technological developments, various kinds of the latest technological inventions and various applications offered by each company will continue to compete. And not just one Korean drama streaming application, but many other streaming applications that have sprung up and can make users hesitate to choose a streaming application to watch quality Korean dramas. The selection of useful criteria for selecting Korean drama streaming applications using the Analytical Hierarchy Process approach and processing using Expert Choice software allows streaming application users to know how to choose a streaming application to watch Korean dramas as desired. The population of this study is the people of Bekasi city with 30 questionnaires. From the results of the study, it was found that VIU is a strategic alternative for selecting Korean drama streaming applications using the Analytical Hierarchy Process which gets top priority with a weight of 0.499 or comparable to $49.9 \%$ of other alternatives..

Keywords: Analytical Hierarchy, Korean Drama Process, Streaming application 


\section{Pendahuluan}

Aplikasi adalah program yang dibuat untuk membuat sesuatu yang bermanfaat dan dapat mempermudah pekerjaan manusia dalam segala bidang. Aplikasi yang bermanfaat adalah aplikasi yang dapat digunakan semaksimal mungkin untuk mencapai tujuannya. Aplikasi streaming video saat ini semakin populer di ranah Tanah Air, ini yang disebut layanan video-ondemand. Layanan tersebut membutuhkan konektivtas internet yang selalu aktif serta harus melakukan pembayaran untuk memgakses ke kelas premiumnya.Pada pertengahan tahun 2015 hadir konten digital yang berbasis Aplikasi streaming film di Indonesia. Aplikasi tersebut menyediakan berbagai macam film salah satunya adalah Drama Korea dengan terjemahan bahasa Indonesia dan bisa dinikmati secara online. Aplikasi streaming tersebut berkembang sangat cepat dan menyediakan berbagai fasilitas.

Akan tetapi bukan hanya satu aplikasi streaming drama Korea, melainkan muncul beberapa macam aplikasi streaming drama Korea antara lain VIU, HOOQ dan Netflix yang masing - masing menawarkan kriteria berbeda - beda sehingga memunculkan fasilitas dan kualitas yang berbeda juga dan menambah daya saing antara sesama aplikasi streaming drama Korea.

Kemampuan dan kehandalan tablet yang dikhususkan untuk gaming mempengaruhi harga tablet itu sendiri, semakin tingi harga sebuah tablet tersebut dipastikan memiliki kualitas yang baik. setiap orang sering di hadapkan pada suatu keadaan dimana orang tersebut harus memutuskan untuk memilih satu dari beberapa pilihan yang ada. Suatu masalah dalam kehidupan dapat diselesaikan dengan berbagai cara yang mungkin saja memberikan pemecahan masalah secara langsung atau memberi beberapa alternatif solusi untuk pemecahan masalah. Penggunaan Sistem Pendukung Keputusan dalam memilih jenis tablet yang sesuai dengan kriterian dan spesifikasi pengunaan, agar memudahkan para calon pengguna tablet memilih jenis tablet sesuai yang diinginkan[1].

Penelitian ini merujuk pada penelitian yang pernah ada sebelumnya yaitu "Sistem Pendukung Keputusan Pemilihan Tablet Gaming dengan Menggunakan Analytical Hierarchy Process" dimaksudkan untuk membantu gamer memilih jenis tablet yang sesuai dengan kriteria dan spesifikasi penggunaan, agar memudahkan para calon pengguna tablet memilih jenis tablet sesuai dengan yang diinginkan. Untuk memberikan solusi yang terbaik dalam pemilihan tablet gaming dan berdasarkan hasil evaluasi yang menunjukkan bahwa Google Nexus 9 merupakan kriteria merek tablet gaming yang paling diminati responden kemudian Ipad 2 Air, Lenovo Yoga 3 Pro dan Sony Xperia Tab Z2[1]. Pada penelitian pemilihan aplikasi streaming drama korea juga dimaksudkan untuk membantu masyarakat penikmat drama korea yang sedag tren di kalangan remaja hingga orang dewasa, penelitian ini mampu memberikan solusi bagi masyarakat khususnya penikmat drama korea untuk bisa menggunakan aplikasi streaming yang sesuai dengan kriteria yang digunakan. "Sistem Pendukung Keputusan Pemilihan Laptop Untuk Kebutuhan Operasional Dengan Metode AHP (Studi Kasus: Direktorat Pembinaan Kursus dan Pelatihan KEMDIKBUD)" penelitian ini membahas sistem pendukung keputusan yang diharapkan dapat membantu karyawan di Direktorat Pembinaan Kursus dan Pelatihan Kemdikbud dalam memilih laptop yang sesuai dengan kebutuhan mereka. Hasil dari penelitian ini menyatakan bahwa leptop yang terpilih dan yang berpotensi untuk Direktorat Pembinanan Kursus dan Pelatihan Kemdikbud adalah Laptop ASUS X450JB-WX001D, Laptop HP Pavilion 14-AB034TX dan Laptop LENOVO IdeaPad G40-80HJID[2].Penelitian selanjutnya meneliti tentang "Sistem Pendukung Keputusan Pemilihan Mahasiswa Berprestasi di STMIK Atma Luhur Pangkalpinang dengan Menggunakan Metode Analytical Hierarchy Process (AHP)" penelitian ini menggunakan metode sistem pengambilan keputusan (Decision Support System). Dalam penelitian ini bertujuan untuk memberikan solusi dalam pemilihan mahasiswa berprestasi di STMIK ATMA LUHUR. Karena dalam pesrsaingan dunia kerja dibutuhkan lulusan yang memiliki kemampuan hard skill dan soft skills yang seimbang, sehingga mahasiswa dituntut untuk aktif dam memiliki prestasi di bidang akademik dan non akademik[3]. Penelitian lainnya yang berjudul "Implementasi Metode AHP Pada Keputusan Penentuan Kelayakan Pinjaman Dana BMT" penelitian ini menggunakan metode sistem penunjang keputusan yang bertujuan untuk membantu Manajer dalam mengambil keputusan penilaian nasabah penerima pinjaman dana berdasarkan kriteria yang berlaku di BMT. Dan dapat menjadi solusi untuk membantu dalam proses pengambilan keputusan penerimaan calon nasabah mengajukan dana, dengan metode AHP[4]. Penelitian berikutnya membahas tentang "Pemilihan Supplier Tembakau Dengan Menggunakan Metode Analytical Hierarchy Process Pada PT.XYZ di 
Surakarta" penelitian ini bertujuan untuk menyelesaikan masalah dalam pemilihan pemasok tembakau pada PT.XYZ. penelitian ini dilakukan sehingga dapat menentukan pemasok mana yang terbaik untuk memenuhi kebutuhan tembakau yang diperlukan oleh perusahaan. Hasil yang didapat dari penelitian menggunakan metode AHP ini adalah urutan prioritas pemasok tembakau terbaik bagi perusahaan[5]. Penelitian pada tahun 2020 yaitu Penggunaan metode Analytical Hierarchy Process (AHP) untuk mengetahui pemilihan aplikasi meeting online yang tepat sesuai dengan prioritas kriteria yang dibutuhkan oleh para pekerja WFH. Metode AHP mampu memberikan urutan terbaik yang akan menghasilkan kriteria dan alternatif dengan bobot nilai tertinggi. Penelitian dilakukan berdasarkan atas kriteria fitur aplikasi, kemudahan pemakaian, jumlah partisipan, durasi waktu, kebutuhan bandwidth, dan keamanan aplikasi. Hasilnya untuk alternatif dengan hasil prioritas adalah aplikasi Zoom dengan nilai tertinggi 0,341 $(34,1 \%)$, disusul oleh Google Meet dengan nilai 0,319 (31,9\%), pada urutan ketiga Skype nilai $0,187(18,7 \%)$ dan yang terakhir Webex dengan nilai $0,153(15,3 \%)[6][6]$.

Penelitian yang dilakukan oleh Ria Resti dan Nani Agustina yaitu menganalisa keputusan Pemilihan Aplikasi Chatting Untuk Group Pada Pengguna Smartphone Android Dengan Metode Analytic Hierarchy Process (AHP). Alternatif yang digunakan adalah aplikasi WhatsApp, Line, dan BBM. Hasil penelitian yang dilakukan berdasarkan kriteria jumlah pemakai, fitur, kecepatan akses, dan kemudahan pemakai guna mendapatkan hasil prioritas aplikasi chatting untuk group yang dipilih oleh para pengguna smartphone android adalah Whatsapp dengan nilai tertinggi $0,355(35,5 \%)$, disusul oleh BBM dengan nilai 0,333 (33.3\%), dan terakhir adalah LINE dengan nilai $0,312(31.2 \%)[7]$. Pada penelitian pemilihan aplikasi streaming drama korea juga dimaksudkan untuk membantu masyarakat penikmat drama korea yang sedag tren di kalangan remaja hingga orang dewasa, penelitian ini mampu memberikan solusi bagi masyarakat khususnya penikmat drama korea untuk bisa menggunakan aplikasi streaming yang sesuai dengan kriteria yang digunakan

Penelitian yang dilakukan oleh Jeffry Andhika Putra dan Tsabit Rakhman menerapkan analisis perbandingan dua metode, yaitu metode Analytic Hierarchy Process (AHP) dan TOPSIS dengan pengujian analisis perhitungan yang digunakan untuk membandingkan tiga aplikasi FOS sistem informasi akademik, diantaranya Sistem Informasi Akademik Kampus (Siakad), Sistem Informasi Akademik Terpadu (Sikadu) dan SISFOKOL untuk mengembangkan sistem informasi akademik pada Jurusan Teknik Informatika Universitas Janabadra. Hasil yang diperoleh pada perangkingan dengan menggunakan dua metode FOS, Siakad berada pada prioritas pertama untuk dipilih dan hasil perbandingan Metode AHP 99,99724875 serta metode TOPSIS 99,9946825, Metode Analytic Hierarchy Process (AHP) lebih relevan digunakan dibanding TOPSIS dengan tingkat kesesuaian lebih tinggi[8].

Dari uraian penelitian diatas menjelaskan bahwa Sistem Pendukung Keputusan dapat digunakan untuk menentukan Aplikasi Streaming Film Drama Korea terbaik dengan memperhatikan alternatif dan kriteria yang digunakan.

\section{Metode Penelitian}

Penelitian ini diawali dengan pengamatan dan penerapan metode Analytical Hierarchy Process (AHP) dalam pemilihan aplikasi streaming. Penelitian ini menyajikan rangkuman wawancara dan hasil survey yang berupa kuesioner. Dengan ini akan digambarkan kondisi pemilihan aplikasi streaming yang ada di lingkungan Kota Bekasi saat ini. Selanjutnya dilakukan pencarian data sekunder yang ada dilapangan melalui berbagai media, seperti: internet. Literatur dan jurnal serta artikel-artikel sehingga didapatkan informasi yang akurat mengenai pemilihan aplikasi streaming dengan menggunkan metoge AHP. Selain itu juga dilakukan identifikasi sistem dengan pertimbangkan variabel-variabel pendukung penerapan AHP dengan cara melakukan wawancara dan pemberian kuesioner.Berdasarkan hasil wawancara mengenai data, selanjutnya diolah dengan menggunakan pendekatan proses Analytical Hierarchy Process (AHP) untuk mendapatkan hasil berupa langkah-langkah yang harus dilakukan pada penerapan AHP. Keputusan yang diperoleh harus segera ditindak lanjuti berupa tindakan atau dapat dengan cara dikaji ulang keputusan tersebut bila ternyata diperoleh informasi baru, yang dapat mempengaruhi hasil untuk mengurangi ketidak pastian, maka akan diperoleh keputusan yang baru.

Instrumen penelitian adalah suatu alat yang digunakan mengukur fenomena alam maupun sosial yang diamati[1]. Secara spesifik semua fenomenal ini disebut variabel penelitian. Instrumen penelitian ini berupa angket yang menyangkut data primer dan skunder untuk 
menentukan prioritas langkah-langkah penerapa metode Analytical Hierarchy Process (AHP) dalam pemilihan aplikasi streaming dengan menggunakan Expert Choice. Data yang dikumpulkan dalam penelitian digunakan untuk menguji hipotesis atau jawaban pertanyaan yang telah dirumuskan. Karena data yang diperoleh akan dijadikan landasan dalam mengambil kesimpulan, data yang dikumpulkan haruslah data yang benar. Agar data yang dikumpulakan baik dan benar, instrumen pengumpulan datanya pun harus baik. Ada beberapa instrumen pengumpulan data yang akan dibahas berikut ini sesuai dengan teknik pengumpulan data

Penulis memerlukan sejumlah data sebagai bahan-bahan masukan yang mampu mendukung penulisan skripsi ini. Data-data tersebut diperoleh dari: Observasi yakni Penulis melakukan pengamatan langsung terhadap objek penelitian di kalangan remaja untuk mendapatkan data dan informasi yang diperlukan untuk mengetahui fasilitas dan kualitas yang ada pada aplikasi streaming. Wawancara, penulis melakukan tanya jawab dengan pengguna penggunanya untuk mendapatkan informasi yang lengkap dan jelas. selanjutnya penulis melakukan studi melalui referensi yang ada pada buku-buku dan mencari tahu bagaimana cara mengaplikasikan dan menggunakan metode yang akan digunakan oleh penulis. Hipotesis yang penulis ajukan adalah sebagai berikut : $\mathrm{H} 0.1$ : tidak terdapat pengaruh kualitas pada aplikasi streaming drama Korea, H1.1 : Terdapat pengaruh kualitas yang bagus pada aplikasi streaming drama Korea, H0.2 : Tidak terdapat pengaruh biaya premium pada aplikasi streaming drama Korea, H1.2 : Terdapat pengaruh biaya premium pada alikasi streaming drama Korea.

Metode Analitycal Hierarcy Process (AHP) dikembangkan awal tahun 1970-an oleh Thomas L. Saaty, seorang ahli matematika dari Universitas Pittsburg. Analisis ini ditunjukan untuk membuat suatu model permasalahan yang tidak mempunyai struktur, biasanya dtetapkan oleh masalah yang terukur (kuantitatif). Masalah yang memerlukan pendapat (judgement) maupun oada situasi yang kompleks atau tidak terkerangka [3]. Pada situasi dimana data statistik sangat minim atau tidak ada sama sekali dan hanya bersifat kualitatif yang didasari oleh persepsi, pengalaman atau intuisi. Model AHP memakai persepsi manusia yang dianggap "expert" sebaga input utamanya. Kriteria "expert" disini bukan berarti orang tersebut haruslah jenius, pintar, bergelar doktor dan sebagainya tetapi lebih mengacu pada orang yang mengerti benar permasalahan yang dilakukan, merasakan akibat suatu masalah atau punya kepentingan terhadap masalah tersebut.Terdapat empat aksioma-aksioma yang terkandung dalam model AHP[1] yaitu:Reciprocal Comparison adalah pengambil keputusan harus dapat membuat perbandingan dan menyatakan preferensinya. Preferensi tersebut harus memenuhi syarat reciprocal yaitu apabila $A$ leih disukai dari pada $B$ dengan skala $x$, maka $B$ lebih disukai dari pada $A$ dengan skala $1 / x$. Homogeneity adalah preferensi seseorang harus dapat dinyatakan dalam skala atau dengan kata lain elemen-elemennya dapat dibandingkan satu sama lainnya. Kalau aksioma ini tidak dipenuhi maka elemen-elemen yang dibandingkan tersebut tidak homogeneity dan harus dibentuk ckuster (kelompok elemen) yang baru. Independence adalah preferensi dinyatakan dengan mengasumsikan bahwa kriteria tidak dipengaruhi oleh alternatifalternatif yang ada melainkan oleh objektif keseluruhan. Ini menunjukkan bahwa pola ketergantungan dalam AHP adalah searah, maksudnya perbandingan antara elemen- elemen dalam satu tingkat dipengaruhi atau tergantung oleh elemen- elemen pada tingkat dasarnya. Exception adalah untuk tujuan pengambilan keputusan. Struktur hirarki diasumsikan lengkap, apabila asumsi ini tidak dipenuhi maka pengambilan keputusan tidak memakai seluruh kriteria atau objektif yang tersedia atau diperlukan sehingga keputusan yang diambil dianggap tidak lengkap.

\section{Hasil dan Pembahasan}

Penelitian ini diawali dengan pengamatan dan penerapan metode Analytical Hierarchy Process (AHP) dalam pemilihan aplikasi streaming. Penelitian ini menyajikan rangkuman wawancara dan hasil survey yang berupa kuesioner. Dengan ini akan digambarkan kondisi pemilihan aplikasi streaming yang ada di lingkungan Kota Bekasi saat ini. Selanjutnya dilakukan pencarian data sekunder yang ada dilapangan melalui berbagai media, seperti: internet. Literatur dan jurnal serta artikel-artikel sehingga didapatkan informasi yang akurat mengenai pemilihan aplikasi streaming dengan menggunkan metoge AHP. Selain itu juga dilakukan identifikasi sistem dengan pertimbangkan variabel-variabel pendukung penerapan AHP dengan cara melakukan wawancara dan pemberian kuesioner. Berdasarkan hasil wawancara mengenai data, selanjutnya diolah dengan menggunakan pendekatan proses Analytical Hierarchy Process (AHP) untuk mendapatkan hasil berupa langkah-langkah yang harus dilakukan pada penerapan 
AHP. Keputusan yang diperoleh harus segera ditindak lanjuti berupa tindakan atau dapat dengan cara dikaji ulang keputusan tersebut bila ternyata diperoleh informasi baru, yang dapat mempengaruhi hasil untuk mengurangi ketidak pastian, maka akan diperoleh keputusan yang baru. Instrumen penelitian adalah suatu alat yang digunakan mengukur fenomena alam maupun sosial yang diamati. Secara spesifik semua fenomenal ini disebut variabel penelitian[6]. Instrumen penelitian ini berupa angket yang menyangkut data primer dan skunder untuk menentukan prioritas langkah-langkah penerapa metode Analytical Hierarchy Process (AHP) dalam pemilihan aplikasi streaming dengan menggunakan Expert Choice.Data yang dikumpulkan dalam penelitian digunakan untuk menguji hipotesis atau jawaban pertanyaan yang telah dirumuskan. Karena data yang diperoleh akan dijadikan landasan dalam mengambil kesimpulan, data yang dikumpulkan haruslah data yang benar. Agar data yang dikumpulakan baik dan benar, instrumen pengumpulan datanya pun harus baik. Ada beberapa instrumen pengumpulan data yang akan dibahas berikut ini sesuai dengan teknik pengumpulan data. Angket atau kuesioner merupakan suatu teknik atau cara pengumpulan data secara tidak langsung (peneliti tidak langsung bertanya-jawab dengan responden). Instrumen atau alat pengumpulan datanya juga disebut angket berisi sejumlah pertanyaan atau pernyataan yang harus dijawab atau direspon oleh responden. Angket (questionnaire) adalah daftar pertanyaan yang diberikan kepada orang lain bersedia memberikan respon (responden) sesuai dengan permintaan pengguna. Dokumentasi adalah ditujukan untuk memperoleh data langsung dari tempat penelitia, meliputi buku-buku, peraturan-peraturan, laporan kegiatan, foto-foto, data yang relevan penelitian. Dokumen merupakan catatan peristiwa yang sudah berlalu, dokumen bisa berbentuk tulisan, gambar atau karya-karya monumental dari seseorang.

Analisis data yang digunakan dalam penelitian ini adalah metode Analytical Hierarchy Process (AHP). Perhitungan bisa dilakukan secara manual maupun dengan bantuan Software Expert Choice. Langkah-langkah dalam pemilihan transportasi online adalah sebagai berikut: Menyusun sruktur hirarki masalah, dalam metode AHP kriteria biasanya disusun dalam bentuk hirarki. Kriteria dan subkriteria dalam penelitian ini merupakan kriteria dan subkriteria yang digunakan pengguna aplikasi streaming dalam memilih aplikasi. Masalah pemilihan ini disusun dalam tiga level hirarki seperti gambar 2. Level 0 merupakan tujuan, level pertama merupakan kriteria dalam pemilihan aplikasi streaming, level 2 merupakan subkriteria, sedangkan level 3 merupakan alternatif aplikasi mana yang akan dipilih. Berikut ini ditampilkan model hirarki dan keputusan analisa metode Analytical Hierarchy Process dalam memilih aplikasi streaming nonton drama Korea.

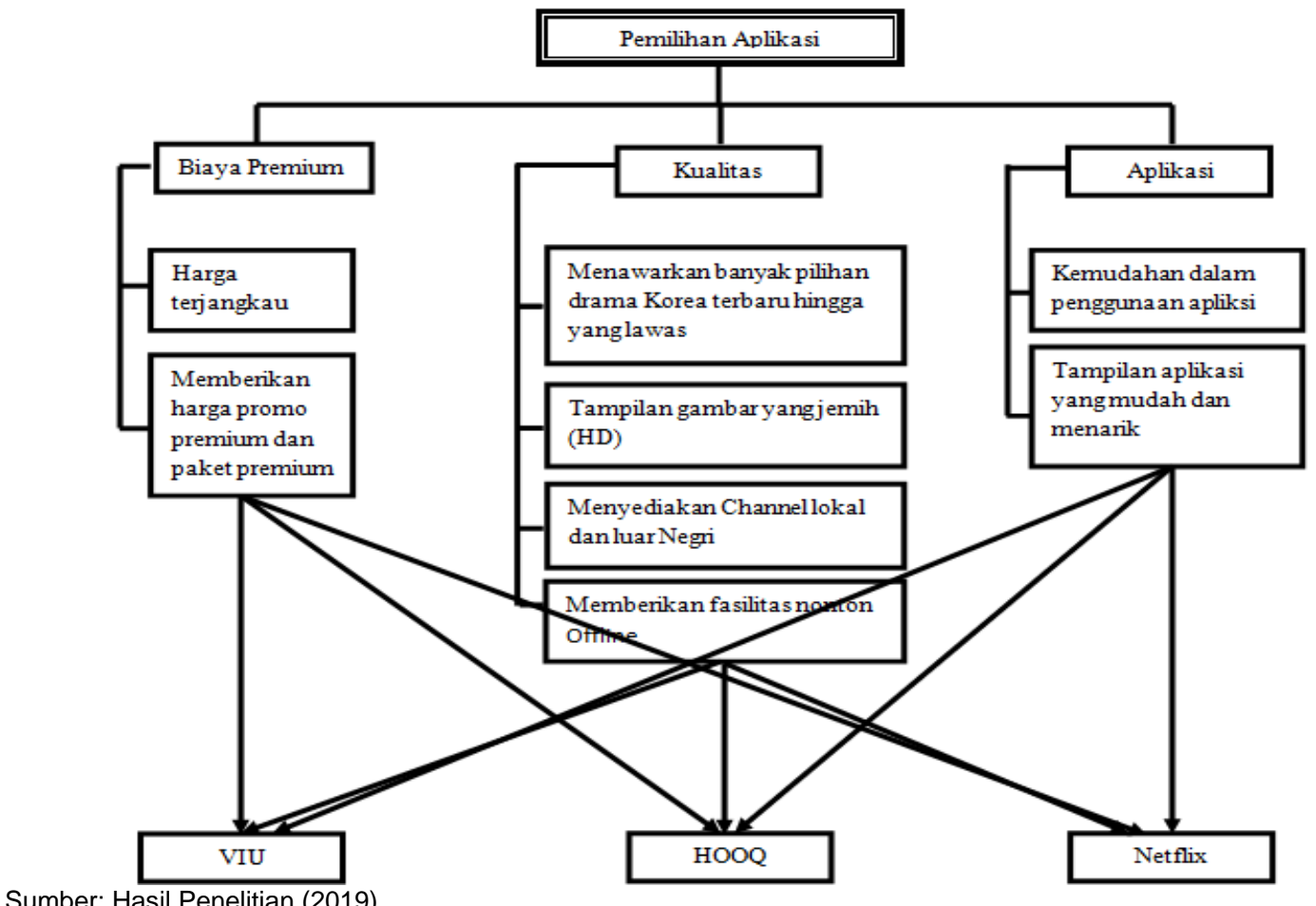

Gambar 1. Struktur Hirarki Masalah 
Pada gambar 1 menggambarkan struktur hirarki masalah dengan langkah-langkah sebagai berikut: Membuat matriks perbandingan berpasangan yang menggambarkan kontribusi relatif pengaruh setiap elemen terhadap masing-masing tujuan kriteria yang setingkat diatasnya, Menghitung bobot/prioritas dari masing-masing variabel pada level 1 (kriteria) yaitu Harga, Kualitas dan Aplikasi, Membuat perbandingan berpasangan dari masing-masing kriteria, Hasil dari setiap perbandingan berpasangan (pairwise comparison), Bagi masing-masing elemen pada kolom tertentu dengan nilai jumlah kolo, tersebut, Hasil tersebut kemudian dinormalisasi untuk mendapatkan vector eigen matriks dengan merata-ratakan jumlah baris terhadap tiga kriteria. Perhitungan di atas menunjukan vector eigen yang merupakan bobot proiritas kriteria terhadap tujuan, Menghitung Rasio Konsisten dengan langkah sebagai berikut: Kalikan nilai matriks perbandingan awal dengan bobot, Membagi jumlah basir hasil perkalian nilai matriks perbandingan awal dengan bobot, Menghitung $\lambda$ maks dengan menjumlahkan hasil pembagian diatas dibagi dengan $\mathrm{n}$, Menghitung Indeks Konsisten dalam persoalan pengambilan keputusan, penting untuk mengetahui konsisten dari sebuah persepsi. Adapun indikator dari konsisten dapat diukur melalui $\mathrm{Cl}$ yang dirumuskan: $\mathrm{Cl}=(\lambda$ maks $-\mathrm{n}) /(\mathrm{n}-1)$.

Dengan: $\mathrm{Cl}=$ indeksi konsistensi, $\lambda$ maks $=$ eigenvalue maksimum $\mathrm{n}=$ orde matriks, Menghitung Rasio Konsistensi AHP mengukur konsistensi menyeluruh dari berbagai pertimbangan melalui suatu rasio konsistensi yang dirumuskan: $\mathrm{CR}=\mathrm{Cl} / \mathrm{RI}$. Dengan: $\mathrm{CR}=$ Rasio konsistensi $\mathrm{RI}=$ Indeks random Pengukuran konsistensi ini dimaksudkan untuk melihat ketidakkonsistenan respon yang diberikan responden. Jika $\mathrm{CR}<0,1$ maka nilai perbandingan berpasangan pada matriks kriteria yang diberikan konsisten. Jika CR $>0,1$ maka nilai pebandingan berpasangan pada matriks kriteria yang diberikan tidak konsisten. Sehingga jika tidak konsisten, maka pengisian nilai-nilai pada matriks berpasangan pada unsur krireria maupun alternatif harus diulang, Menghitung bobot/prioritas dari masing-masing variabel pada level 2 (subkriteria) dari masing-masing kriteria dalam pemilihan aplikasi streaming sepeti langkah 3 di atas, Kemudian ditentukan global priority/prioritas global dengan cara mengalikan local priority/prioritas dari masing-masing subkriteria dengan prioritas kriteria, Menghitung bobot/prioritas dari masing-masing variabel pada level 3 (alternatif) yaitu bobot setiap aplikasi streaming dibandingkan dengan masing-masing subkriteria seperti langkah 3 di atas, Setelah mengetahui bobot dari masing-masing subkriteria dan bobot dari masing-masing aplikasi streaming kemudian ditentukan aplikasi streaming mana yang akan dipilih. Nilai keseluruhan dari masing-masing, yaitu jumlah keseluruhan dari perkalian bobot aplikasi streaming dengan bobot subkriteria. Aplikasi streaming yang dipilih adalah aplikasi streaming yang memiliki nilai paling tinggi.

Adapun proses pengolahan, analisa dan interprestasi data ini didahului dengan menentukan elemen-elemen yang signifikan pada masing-masing kriteria- kriteria beserta subsub kriterianya. Dimulai dari: Penentuan tujuan utama "Pemilihan Aplikasi Streaming Drama Korea", Kriteria-kriteria "Harga Premium, Kualitas, Aplikasi", Sub-sub kriteria "Harga terjangkau, Memberikan harga promo premium dan paket premium, menawarkan banyak pilihan drama Korea terbaru hingga yang lawas, tampilan gambar yang jernih (HD), menyediakan Channel lokal dan luar negri, memberikan fasilitas nonton Offline, kemudahan dalam penggunaan aplikasi, tampilan aplikasi yang mudah dan menarik", Alternatif "VIU, HOOQ, Netflix" dari strategis penerapan dengan menggunakan metode AHP dalam pemilihan aplikasi streaming drama Korea. Selanjutnya dilakukan untuk menjawab rumusan masalah sesuai yang diajukan berdasarkan proses hirarki analitis. Landasan Kriteria yang Menjadi Pertimbangan Pemilihan Aplikasi Streaming Drama Korea Ditinjau dari Elemen Kriteria dan Sub- kriteria Berikut ini adalah bobot masing-masing kriteria yang mempengaruhi penentuan dalam pemilihan aplikasi streaming drama Korea dari para responden: 
Prioitities with respectto:

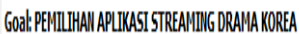

Biaya Premiun

Kulitbs

Aplikas

Inconistency $=0,04$

witho nissing judgments,

Sumber: Hasil Penelitian (2019)

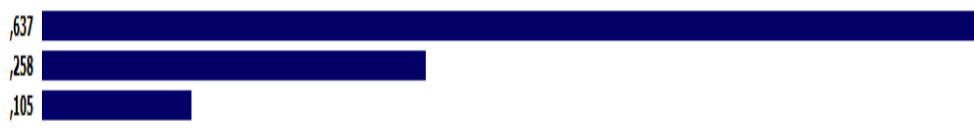

\section{Gambar 2. Kriteria Beserta Nilai Bobotnya}

Pada Gambar 2 menjelaskan tentang Kriteria pertama yang mempengaruhi penentuan pemilihan aplikasi streaming drama Korea adalah "Biaya Premium" (nilai bobot 0,637 atau sebanding dengan $63,7 \%$ dari total kriteria), Kriteria kedua yang mempengaruhi penentuan pemilihan aplikasi streaming drama Korea adalah "Kualitas" (nilai bobot 0,258 atau sebanding dengan $25,8 \%$ dari total kriteria), Kriteria ketiga yang mempengaruhi penentuan pemilihan aplikasi streaming drama Korea adalah "Aplikasi" (nilai bobot 0,105 atau sebanding dengan $10,5 \%$ dari total kriteria). Prioritas Kepentingan dari Masing-Masing Variabel Kriteria dalam pemilihan aplikasi streaming drama Korea Dari hasil perhtiungan perbandingan berpasangan antar variabel dalam memilih Aplikasi Streaming diperoleh prioritas kepentingan dan bobot yang ditunjukkan dalam tabel berikut ini:

Tabel 1. Prioritas Kepentingan Kriteria dalam Pemilihan Aplikasi Streaming Drama Korea

\begin{tabular}{lll}
\hline Kriteria & Bobot & Prioritas \\
\hline Biaya premium & 0,637 & I \\
\hline Kualitas & 0,258 & II \\
\hline Aplikasi & 0,105 & III \\
\hline
\end{tabular}

Sumber: Hasil Pengolahan AHP

Sub-kriteria dalam pemilihan aplikasi streaming drama Korea dengan Kriteria Biaya Premium, dari hasil perhitungan perbandingan berpasangan antar variabel dalam kriteria biaya premium diperoleh prioritas kepentingan dan bobot yang ditunjukkan dalam tabel berikut ini:

Tabel 2.Prioritas Kepentingan Sub-kriteria Biaya Premium dalam Pemilihan Aplikasi Streaming Drama Korea

\begin{tabular}{lc} 
Sub-kriteria & Bobot \\
\hline Harga Terjangkau & 0,883 \\
\hline Memberkan premium harga promo premium dan paket & 0,167
\end{tabular}

Sumber: Hasil Pengolahan AHP

Kriteria Kualitas Pelayanan, Dari hasil perhitungan perbandingan berpasangan antar variabel dalam kriteria kualitas diperoleh prioritas kepentingan dan bobot yang ditunjukkan dalam tabel berikut ini:

Tabel 3.Prioritas Kepentingan Sub-kriteria Kualitas dalam Pemilihan Aplikasi Streaming Drama Korea

\begin{tabular}{lll}
\hline Sub-kriteria & Bobot & Prioritas \\
\hline $\begin{array}{l}\text { Memberikan banyak pilihan drama } \\
\text { korea }\end{array}$ & 0,394 & I \\
\hline Tampilan gambar yang jernih (HD) & 0,287 & II \\
\hline $\begin{array}{l}\text { Menawarkan banyak pilihan drama } \\
\text { Korea }\end{array}$ & 0,223 & III \\
\hline $\begin{array}{l}\text { Menyediakan fasilitas lokal dan } \\
\text { luar negeri }\end{array}$ & 0,096 & IV \\
$\begin{array}{l}\text { Sumber: Hasil Pengolahan AHP } \\
\text { Mum }\end{array}$ & &
\end{tabular}


Inconsistency ratio atau rasio inkonsistensi data responden ahli merupakan parameter yang digunakan untuk memeriksa apakah perbandingan berpasangan telah dilakukan dengan konsekuen atau tidak. Rasio inkonsistensi data dianggap baik jika nilai CR-nya $\leq 0,1$. Untuk memeriksa rasio inkonsistensi data responden, berikut ini ditampilkan nilai rasio inkonsistensi pada masing-masing matriks perbandingan dari sisi Biaya Premium:

Tabel 4. Rasio Inkonsistensi perbandingan antara elemen matriks penggabungan data responden ahli

\begin{tabular}{|c|c|c|}
\hline No. & Matriks Perbandingan Elemen & Nilai CR \\
\hline 1. & $\begin{array}{c}\text { Perbandingan elemen kriteria level } 1 \text { Biaya premium berdasarkan } \\
\text { strategi } \quad \text { Pemilihan aplikasi } \\
\text { Streaming drama Korea }\end{array}$ & 0,04 \\
\hline 2. & $\begin{array}{l}\text { Perbandingan elemen kriteria level } 2 \text { berdasrkan } \\
\text { sasaran kriteria: Strategi Biaya premium - Harga Terjangkau }\end{array}$ & 0,01 \\
\hline 3. & $\begin{array}{l}\text { Perbandingan elemen kriteria level } 2 \text { berdasarkan sasaran kriteria: Strategi } \\
\text { Biaya premium - Memberikan harga promo premium dan paket } \\
\text { premium }\end{array}$ & 0,00352 \\
\hline 4. & $\begin{array}{l}\text { Perbandingan elemen berdasarkan sasaran straming drama Korea kriteria } \\
\text { Strategi level } \quad 1 \text { Pemilihan Kualitas aplikasi }\end{array}$ & 0,06 \\
\hline 5. & $\begin{array}{l}\text { Perbandingan elemen kriteria level } 2 \text { berdasarkan sasaran kriteria: Strategi } \\
\text { Kualitas - Menawarkan banyak pilihan drama Korea terbaru hingga yang } \\
\text { lawas }\end{array}$ & 0,00887 \\
\hline 6. & $\begin{array}{l}\text { Perbandingan elemen kriteria level } 2 \text { berdasarkan sasaran kriteria: Strategi } \\
\text { Kualitas - Tampilan gambar } \\
\text { yang jernih (HD) }\end{array}$ & 0,03 \\
\hline 7. & $\begin{array}{l}\text { Perbandingan elemen kriteria level } 2 \text { berdasarkan } \\
\text { sasaran kriteria: Strategi Kualitas - Menyediakan Channel lokal dan luar } \\
\text { Negeri }\end{array}$ & 0,04 \\
\hline 8. & $\begin{array}{l}\text { Perbandingan elemen kriteria level } 2 \text { berdasarkan } \\
\text { sasaran kriteria: Strategi Kualitas - Memberikan fasilitas nonton offline }\end{array}$ & 0,05 \\
\hline 9. & $\begin{array}{l}\text { Perbandingan elemen berdasarkan } \quad \text { sasaran streaming drama } \\
\text { Korea kriteria strategi level } 1 \text { Pemilihan Aplikasi aplikasi }\end{array}$ & 0 \\
\hline 10. & $\begin{array}{l}\text { Perbandingan elemen kriteria level } 2 \text { berdasarkan } \\
\text { sasaran kriteria: Strategi Aplikasi - Kemudahan dalam penggunaan aplikasi }\end{array}$ & 0,00669 \\
\hline 11. & $\begin{array}{l}\text { Perbandingan elemen kriteria level } 2 \text { berdasarkan } \\
\text { sasaran kriteria: Strategi Aplikasi - Tampilan aplikasi yang mudah dan menarik }\end{array}$ & 0,00887 \\
\hline
\end{tabular}

Sumber: Hasil Pengolahan AHP

Dapat disimpulkan bahwa perbandingan berpasangan yang diberikan responden ahli memiliki rasio inkonsistensi yang lebih kecil dari 0,1 sebagai batas maksimum nilai rasio inkonsistensi. Dengan demikian hasil perhitungan geometrik gabungan data responden cukup konsisten. Hipotesa I: Berdasarkan hasil Kuesioner yang telah disebarkan Sistem Pendukung Keputusan dalam menetukan Pemilihan Aplikasi Streaming Drama Korea yang tepat pada Masyarakat Kota Bekasi dengan menggunakan pendekatan AHP, maka di peroleh informasi bahwa kriteria Biaya Premium adalah kriteria yang mendapat prioritas utama oleh para responden ahli dalam menentukan Aplikasi Streaming Drama Korea yang tepat dengan mendapatkan nilai bobot tertinggi dari kriteria- kriteria yang ada seberar 0.637 atau sebanding dengan $63,7 \%$ dari total kriteria. Selain itu sub-sub kriteria yang mendapat prioritas utama dalam Sistem Pendukung Keputusan dalam menentukan Pemilihan Aplikasi Streaming Drama Korea yang tepat pada Masyarakat Kota Bekasi dengan menggunakan pendekatan AHP adalah sub-kriteria Harga Terjangkau dengan nilai bobot 0,833 atau setara dengan $83,3 \%$ dari total sub-kriteria yang ada, selanjutnya sub-kriteria Memberikan fasilitas nonton offline juga mendapat prioritas utama dengan nilai bobot 0,394 atau setara dengan $39,4 \%$ dari total sub kriteria yang ada. Kemudan sub-sub kriteria terakhir yang mendapat prioritas utama adalah Kemudahan dalam menggunakan aplikasi dengan nilai bobot 0,750 atau setara dengan $75,0 \%$ dari total sub-kriteria yang ada. Dengan demikian dari hasil pengolahan data diatas dapat diambil informasi bahwa $(\mathrm{H} 1)$ diterima. Hipotesa II: Berdasarkan informasi yang diperoleh dari pengolahan data menunjukkan secara keseluruhan bahwa alternatif Aplikasi Streaming drama Korea VIU adalah alternatif yang tepat dengan pilihan yang mendapat prioritas utama dalam menentukan Aplikasi streaming drama Korea dengan bobot sebesar 0,499 atau sebanding dengan $49,9 \%$ dari total alternatif yang ada. Dengan demikian dapat ditarik kesimpulan bahwa $(\mathrm{H} 2)$ diterima. Melakukan perhitungan manual dengan langkah-langkah sebagai berikut: Kriteria 
yang menjadi penentuan yaitu, Biaya Premium, Kualitas dan Aplikasi, Menyusun kriteria-kriteria pemilihan aplikasi streaming dengan matriks perbandingan berpasangan. Masukan awal adalah menentukan nilai kriteria, Menjumlahkan nilai elemen setiap kolom dari nilai elemen matrik kriteria diatas, maka jumlah elemen setiap kolom adalah: Biaya Premium: $1.00+0,33+0.20=1,53$, Kualitas: $3.00+1.00+0.33=4,33$, Aplikasi: $5.00+3.00+1.00=9.00$, Membagikan setiap elemen pada kolom dengan jumlah perkolom yang sesuai dari nilai-nilai elemen matriks perbandingan berpasangan dan jumlah masing- masing kolom diatas, maka dapat dihitung matriks normalisasinya dengan cara membagi setiap elemen pada kolom dengan jumlah perkolom yang sesuai. Setelah matriks normalisasi didapatkan, langkah selanjutnya menunjukkan tiap baris pada matriks tersebut. Jumlah masing-masing baris pada matriks normalisasi kriteria harus 1,00 dan dapat dihitung dengan cara sebagai berikut: Biaya Premium: $\quad 0,65+0,22+0,13=1,00, \quad$ Kualitas: $0,69+0,23+0,08=1,00$, Aplikasi: $0,56+0,33+0,11=1,00$, Setelah didapatkan jumlah pada masing-masing baris, jumlahkan kembali baris selanjutnya dan dihitung nilai prioritas kriteria dengan cara membagi masingmasing jumlah baris dengan jumlah elemen atau jumlah kriteria, sehingga nilai prioritas masingmasing kriteria dapat dihitung sebagai berikut: Nilai prioritas Biaya Premium: $(0,65+0,69+0,56) / 3=0,63$, Nilai prioritas Kualitas: $(0,22+0,23+0,33) / 3=0,26$, Nilai prioritas Aplikasi: $(0,13+0,08+0,11 / 3=0,11$, Menguji konsistensi dengan cara menghitung mengalikan matriks perbandingan berpasangan awal dengan bobot prioritas kriteria, setelah itu menghitung nilai lamda maksimum dengan rumus yaitu mengalikan matriks awal dengan bobot lalu di bagi jumlah baris dengan bobot, Menghitung indeks konsistensi (Consistency Index) dengan menggunakan rumus: $C I=\lambda \max -n / \mathrm{n}-1$, Menghitung Index Random (RI) dengan menggunakan rumus: $R I=1,98(\mathrm{n}-2) / \mathrm{n}: R I=1,98(3-2) / 3=0,66$, Menghitung rasio konsistensi (Consistency Ratio) dengan rumus: $C R=\mathrm{Cl} / \mathrm{IR}$. IR adalah nilai indeks random dengan nilai 0,66 karena pada kasus ini mempunyai ukuran matriks 3 , sehingga nilai dari CR dapat dihitung dengan cara sebagai berikut: $C R=0,02 / 0,66=0,03$. Karena nilai rasio konsistensi $\leq 0,1$ dan hasilnya 0,03 maka matriks dikatakan konsisten. Pengukuran konsistensi ini dimaksudkan untuk melihat ketidakkonsistenan respon yang diberikan responden. Jika $\mathrm{CR}<0,1$ maka nilai perbandingan berpasangan pada matriks kriteria yang diberikan konsisten. Jika CR $>0,1$ maka nilai pebandingan berpasangan pada matriks kriteria yang diberikan tidak konsisten. Sehingga jika tidak konsisten, maka pengisian nilai-nilai pada matriks berpasangan pada unsur krireria maupun alternatif harus diulang.

\section{Kesimpulan}

Penelitian ini akan menunjukan peringkat prioritas alternatif strategis penelitian pemilihan aplikasi streaming drama Korea dilingkungan masyarakat kota Bekasi. Selain itu diperoleh gambaran analisa dari tingkat pengaruh masing-masing kriteria terhadap sub-kriteria dan tingkat pengaruh sub- kriteria terhadap alternatif.Setelah dilakukan pengolahan data menggunakan software Expert Choice11 maka diperoleh kesimpulan penelitian pemilihan aplikasi streaming drama Korea menggunakan Analytical Hierarchy Process dari sisi keriteria biaya premium, kualitas dan aplikasi sebagai berikut: Berdasarkan Kriteria Biaya Premium, "Sub-Kriteria" yang diperlukan untuk menentukan alternatif strategi pemilihan aplikasi streaming drama Korea ,yaitu: Harga biaya premium yang terjangkau, Memberikan harga promo premium dan paket premium. Berdasarkan Kriteria Kualitas, "Sub-Kriteri" yang diperlukan untuk menentukan alternatif strategi pemilihan aplikasi streaming drama Korea: Menawarkan banyak pilihan drama Korea terbaru hingga yang lawas, Tampilan gambar yang jernih (HD), Menyediakan Channel lokal dan luar Negeri, Memberikan fasilitas nonton Offline. Berdasarkan Kriteria Aplikasi, "Sub-Kriteria" yang diperlukan untuk menentukan alternatif strategi pemilihan aplikasi streaming drama Korea: Kemudahan dalam penggunaan aplikasi, Tampilan aplikasi yang mudah dan menarik. Berdasarkan ketiga kriteria Biaya Premium, Kualitas dan Aplikasi. Strategi "Alternatif" yang diperlukan untuk menentukan alternatif strategi pemilihan aplikasi streaming drama Korea: VIU, HOOQ, Netflix. Berdasarkan rasio Biaya Premium, Kualitas dan Aplikasi, VIU merupakan prioritas utama dari alternatif strategi yang diambil sebagai penerapan Pemilihan Aplikasi Streaming Drama Korea. Dengan dilakukannya penelitian ini maka strategi Pemilihan Aplikasi Streaming Drama Korea dengan menggunakan pendekatan AHP menggunakan software Expert Choice 11 dapat diterapkan di Lingkungan Masyarakat Kota Bekasi dan hasil akhirnya adalah pemilihan VIU sebagai prioritas utama dari alternatif strategi yang diambil. 


\section{Daftar Referensi}

[1] A. Salim and B. O. Lubis, "Sistem Pendukung Keputusan Pemilihan Jenis Tablet Gaming dengan Menggunakan Analytical Hierarchy Process," Pros. Semin. Nas. Energi Telekomun. dan Otomasi, no. ISBN: 978-602-74127-4-3, pp. 1-9, 2017.

[2] G. P. Sanyoto, R. I. Handayani, and E. Widanengsih, "Sistem Pendukung Keputusan Pemilihan Laptop Untuk Kebutuhan Operasional Dengan Metode AHP (Studi Kasus: Direktorat Pembinaan Kursus Dan Pelatihan Kemdikbud)," J. Pilar Nusa Mandiri, vol. 13, no. 2, pp. 167-174, 2017.

[3] F. Yani, "Sistem Pendukung Keputusan Pemilihan Mahasiswa Berprestasi di STMIK Atma Luhur Pangkalpinang dengan Menggunakan Metode Analytical Hierarchy Process (AHP)," J. Nas. Teknol. dan Sist. Inf., vol. 2, no. 2, pp. 109-118, 2016, doi: 10.25077/teknosi.v2i2.2016.109-118.

[4] D. Purnia, "Implementasi Metode AHP pada Keputusan Penentuan Kelayakan Pinjaman Dana BMT," J. Technoper, vol. 2, pp. 1-15, 2017.

[5] A. Indrianita, "Calyptra: Jurnal Ilmiah Mahasiswa Universitas Surabaya Vol.5 No.1 (2016)," Calyptra, vol. 2, no. 2, pp. 1-12, 2013.

[6] J. S. Komputer et al., "Pemilihan Aplikasi Meeting Online Untuk Mendukung Work From Home Menggunakan Metode AHP," vol. 4, no. September, pp. 533-544, 2020.

[7] R. Resti, P. Sari, S. Informasi, N. Agustina, and K. Akuntansi, "Analisa Keputusan Pemilihan Aplikasi Chatting Untuk Group Pada Pengguna Smartphone Android Dengan Metode Analytic Hierarchy Process ( AHP )," vol. 19, no. 2, pp. 131-141, 2017.

[8] J. A. Putra et al., "Pemilihan Aplikasi Open Source Sistem Informasi Akademik Menggunakan Model Pengambilan Keputusan AHP serta TOPSIS ( Kasus : Jurusan Teknik Informatika Universitas Janabadra )," pp. 37-44, 2018. 